\title{
Facile Synthesis of Hollow MgO Spheres and Their Fluoride Adsorption Properties
}

\author{
Yong Zhang, ${ }^{1}$ Zhen Jin $\mathbb{D}^{2},{ }^{2}$ Liao Min-He, ${ }^{1}$ Xu Guang-Song, ${ }^{1}$ Xu Min-Da, ${ }^{2}$ Hui Cheng, ${ }^{3}$ \\ and Jian Huang $\mathbb{D}^{1}$ \\ ${ }^{1}$ School of Environment and Energy Engineering, Anhui Jianzhu University, Hefei 230601, Anhui, China \\ ${ }^{2}$ School of Materials and Chemical Engineering, Anhui JianZhu University, Hefei 230601, Anhui, China \\ ${ }^{3}$ Key Laboratory of Xin'an Medicine, Ministry of Education, Anhui Province Key Laboratory of R\&D of Chinese Medicine, \\ Anhui University of Chinese Medicine, Hefei 230038, Anhui, China
}

Correspondence should be addressed to Zhen Jin; ftbjin@hotmail.com and Jian Huang; 117947453@qq.com

Received 25 December 2020; Revised 30 March 2021; Accepted 9 May 2021; Published 19 June 2021

Academic Editor: Markus R. Wagner

Copyright ( 2021 Yong Zhang et al. This is an open access article distributed under the Creative Commons Attribution License, which permits unrestricted use, distribution, and reproduction in any medium, provided the original work is properly cited.

\begin{abstract}
In the present work, the hollow $\mathrm{MgO}$ spheres were synthesized through a facile wet-chemistry method. X-ray diffraction, scanning electron microscopy, transmission electron microscopy, and energy dispersive spectrum are employed to characterize the as-prepared sample. Those results indicate that the average size of the as-prepared $\mathrm{MgO}$ hollow spheres is about $2 \mu \mathrm{m}$. Also, the $\mathrm{MgO}$ hollow spheres have the polycrystalline and porous structure, which would provide large specific surface area and plenty active sites for fluoride adsorption. The adsorption properties of the $\mathrm{MgO}$ hollow spheres towards fluoride are investigated. The fluoride adsorption kinetics of the $\mathrm{MgO}$ hollow spheres fits well the pseudo-second-order model. Also, the kinetic data revealed that the fluoride adsorption was rapid, more than $83 \%$ of fluoride could be removed within $40 \mathrm{~min}$. The fluoride adsorption capacity of the hollow $\mathrm{MgO}$ spheres is larger than $182.4 \mathrm{mg} / \mathrm{g}$ at a $\mathrm{pH}$ of 7.0. The as-prepared products maintain excellent adsorption performance in the $\mathrm{pH}$ range of 3-11. In addition, the adsorption mechanism also has been discussed. From the FTIR results, a hydroxyl and carbonate coexchange mechanism is proposed. It is believed that the hollow $\mathrm{MgO}$ spheres are a potential candidate for fluoride removal.
\end{abstract}

\section{Introduction}

Excessive fluorine in drinking water is one of the world problems [1, 2]. Only in the concentration range of $0.5-1.0 \mathrm{mg} / \mathrm{L}$, fluoride-contained water is good for human health [3]. However, when the concentration of fluorine goes beyond this range, long-term intake of the fluoride-excessive water would cause dental and skeletal fluorosis. Thus, the World Health Organization (WHO) classified fluoride as one of the contaminants in ground water [4]. Over 200 million people drink fluoride-excessive water every day [5]. Many methods have been developed to the remove the excessive fluoride from drinking water, such as precipitation [6], ion exchange $[7,8]$, nanofiltration $[3,9]$, reverse osmosis $[10,11]$, electrodialysis $[12,13]$, and adsorption $[14,15]$. Due to the low cost and simplicity of operation, adsorption seems to be the attractive one among those technologies $[16,17]$. Various absorbents have been investigated for the fluoride removal [18-22]. For example, Zhang et al. applied bauxite in fluoride removal, the adsorption capacity of which is $1.775 \mathrm{mg} / \mathrm{g}$ [19]. $\mathrm{Ku}$ and Chiou studied the defluoride property of the alumina and found that the maximum fluoride removal capacity is $16.3 \mathrm{mg} / \mathrm{g}$ when $\mathrm{pH}=5$ [23]. However, the low adsorption capacity and narrow $\mathrm{pH}$ application range largely restrict the applications of those absorbents [24, 25]. Thus, developing novel fluoride adsorbents with high adsorption capacity, low price, and wide $\mathrm{pH}$ application range is very important.

Magnesium oxide $(\mathrm{MgO})$, as a low-cost absorbent, is attractive in fluoride removal due to its strong affinity, high adsorption capacity, nontoxic nature, and limited solubility in water $[22,26,27]$. It is reported that the $\mathrm{MgO}$ absorbents can efficiently remove fluoride in wide $\mathrm{pH}$ range. Liu found that the fluoride adsorption capacity of pure $\mathrm{MgO}$ was $4.5 \mathrm{mg} / \mathrm{g}$, and the adsorption performance remained stable in the $\mathrm{pH}$ range of 2-10 [28]. Maliyekkal also found that the 
$\mathrm{MgO} / \mathrm{Al}_{2} \mathrm{O}_{3}$ composite can efficiently remove fluoride in the $\mathrm{pH}$ range of 3-10 [29]. However, the adsorption capacity of those absorbents is still limited. Many efforts have been taken to achieve high-performance $\mathrm{MgO}$ absorbents [30]. It is well accepted that the morphology can greatly affect the corresponding adsorption performance [31]. With the development of science and technology, nanostructures always exhibit better properties [32, 33]. Among various nanostructures, hollow and porous nanostructures always possess higher surface area, subsequently bringing more surface defects. Those defects can work as active sites and accordingly increase the adsorption property [34]. Thus, hollow and porous structures are favorable for absorbents. Many pioneer works reported that the hollow-structured $\mathrm{MgO}$ absorbents would exhibit better adsorption properties. Kuang et al. synthesized spherical-like $\mathrm{MgO}$ nanostructures by calcinate magnesium acetate, which exhibited high adsorption performance for metal ions [35]. Song prepared the hierarchical flower-like $\mathrm{MgO}$ hollow spheres extremely through a solvothermal method, which are the excellent arsenic absorbents [36]. However, those methods always require high temperature, high pressure, and complex operation. It is still a big challenge to obtain the $\mathrm{MgO}$ hollow absorbents through a simple method for high-performance fluoride removal. In the present work, the $\mathrm{MgO}$ hollow spheres were synthesized through a facile wet-chemical method. The operation temperature is as lower as $100^{\circ} \mathrm{C}$, and high temperature, high pressure, and autoclave are no longer needed.

The as-prepared $\mathrm{MgO}$ hollow spheres are with the uniform sizes of $2 \mu \mathrm{m}$ in average. Also, the $\mathrm{MgO}$ hollow spheres have the polycrystalline and porous structure, which would provide large specific surface area and plenty active sites for fluoride adsorption. The fluoride adsorption kinetics of the $\mathrm{MgO}$ hollow spheres fits well the pseudo-second-order model. Also, the kinetic data reveal that the fluoride adsorption was rapid, more than $83 \%$ of fluoride could be removed within $40 \mathrm{~min}$. The $\mathrm{MgO}$ hollow spheres can efficiently remove fluoride at the condition of acid, neutral, and even weak alkaline. The adsorption capacity is over $182.4 \mathrm{mg} / \mathrm{g}$ at neutral condition. The fluoride adsorption mechanism of the absorbents is also investigated. It is found that, besides the hydroxyls, the surface carbonates formed during the synthesis process also can be exchanged with fluoride.

\section{Experimental}

2.1. Synthesis. All reagents were purchased from Sinopharm Chemical Reagent Co., Ltd. (China) with analytical grade. In the synthesis process, $1 \mathrm{~g} \mathrm{MgSO}_{4} \cdot 7 \mathrm{H}_{2} \mathrm{O}$ and $3 \mathrm{~g}$ urea were added into the mixed solution of $20 \mathrm{~mL}$ deionized water and vigorously stirred for $10 \mathrm{~min}$. Then, the abovementioned solution was transferred into a $100 \mathrm{~mL}$ conical flask, sealed, and heated at $100^{\circ} \mathrm{C}$ for $720 \mathrm{~min}$. After reaction, the white precipitate was collected by centrifugation. The resultant precipitate was washed and dried at $60^{\circ} \mathrm{C}$. After annealing at $500^{\circ} \mathrm{C}$ for $4 \mathrm{~h}$, the white $\mathrm{MgO}$ hollow spheres can be obtained.
2.2. Characterization. The morphologies of the samples were examined by field-emission scanning electron microscopy (FE-SEM; JEOL JSM-7500F) and high-resolution transmission electron microscopy (HRTEM; FEI Talos F200X). The crystal structure of the samples was determined by $\mathrm{X}$-ray diffraction (XRD; Bruker $\mathrm{D} 8$ ) with $\mathrm{Cu} \mathrm{K} \alpha$ radiation. The infrared spectrum of the samples was tested by Fourier-transform infrared spectrometer (FTIR; Thermo Scientific Nicolet 8700).

2.3. Adsorption Experiments. The fluoride stock solution with the concentration of $1000 \mathrm{ppm}$ was prepared by dissolving $\mathrm{NaF}$ in deionized water and stored under dark conditions at $4^{\circ} \mathrm{C}$. The fluoride standard solutions with different concentrations were prepared by rational dilution of the stock solution. The isotherm adsorption tests were carried out in a centrifuge tubes containing $10 \mathrm{mg}$ absorbent and $10 \mathrm{~mL}$ fluoride solution. Then, the centrifuge tubes were shaked in a shaker at $25^{\circ} \mathrm{C}$ for $12 \mathrm{~h}$. The $\mathrm{pH}$ value was not further adjusted. Then, the upper layer solution was carefully pipetted and filtered through a $0.45 \mu \mathrm{m}$ filter for collection. The fluoride-ion-selective electrode PF-202-CF was applied to measure the residual fluoride concentration of the solution. The residual $\mathrm{MgO}$ hollow spheres were centrifuged, washed, and dried in an oven at $60^{\circ} \mathrm{C}$.

In the kinetics test, the initial fluoride concentration was $10 \mathrm{mg} / \mathrm{L}$, the dose of adsorbents was $1.0 \mathrm{~g} / \mathrm{L}$, and the volume of the fluoride solution was $100 \mathrm{~mL}$. The samples were shaken at $150 \mathrm{rpm}$ in the shaker at $25^{\circ} \mathrm{C}$. At certain time, $6 \mathrm{~mL}$ of supernatant solutions was pipette and centrifuged for the remaining fluoride concentration determination.

In the experiment of $\mathrm{pH}$ effect on fluoride adsorption, the $\mathrm{pH}$ value was adjusted by $\mathrm{HCl}$ and $\mathrm{NaOH}$ solution. In the experiment of the coexisting anions' effects on fluoride adsorption, the concentration of coexisting anions was set as $300 \mathrm{mg} / \mathrm{g}$.

\section{Results and Discussion}

3.1. Characterization. Firstly, the morphology of the $\mathrm{MgO}$ hollow spheres was characterized by SEM. Figure 1(a) presents the SEM image of the MgO hollow spheres. It can be clearly seen that the $\mathrm{MgO}$ hollow spheres are with the uniform sizes of $2 \mu \mathrm{m}$ in average. Figure 1(b) shows the highresolution SEM images of the $\mathrm{MgO}$ hollow spheres. Obviously, the as-prepared $\mathrm{MgO}$ hollow spheres have rough external surface, which is probably due to the chaos accumulation of small nanoparticles. In the direction of the white arrow, the broken spheres can be clearly observed, and the hollow nature of $\mathrm{MgO}$ spheres is verified. During the experimental process, the precursors were firstly synthesized, and then, the $\mathrm{MgO}$ hollow spheres can be obtained after the heat treatment. Figure 1(c) presents the XRD patterns of the precursors and the final $\mathrm{MgO}$ hollow spheres. All peaks of the precursors can be indexed to $\mathrm{Mg}_{5}\left(\mathrm{CO}_{3}\right)_{4}(\mathrm{OH})_{2} \bullet\left(\mathrm{H}_{2} \mathrm{O}\right)_{4}$ hydromagnesium (JCPDS 70-1177) [5]. After annealing at $600^{\circ} \mathrm{C}$ for $2 \mathrm{~h}$ in the air, the XRD pattern has totally changed, which can be indexed to (111), (200), and (220) planes of the 


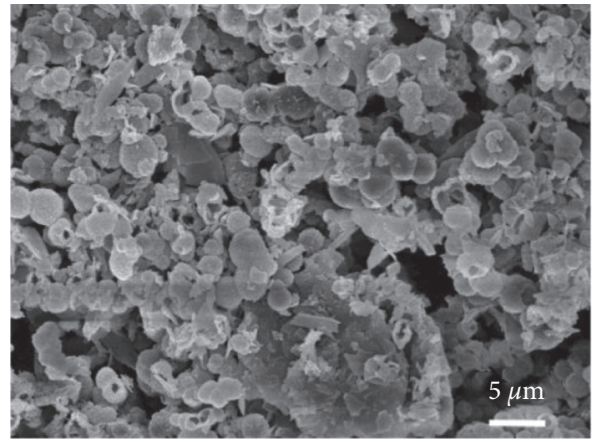

(a)

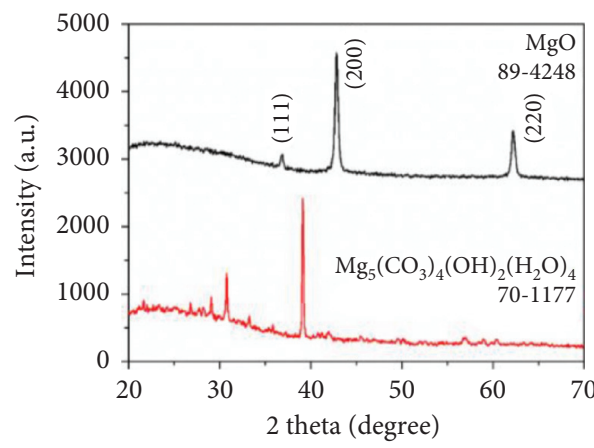

(c)

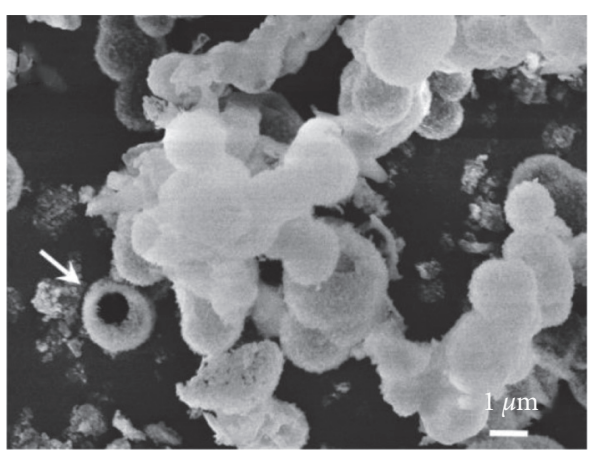

(b)

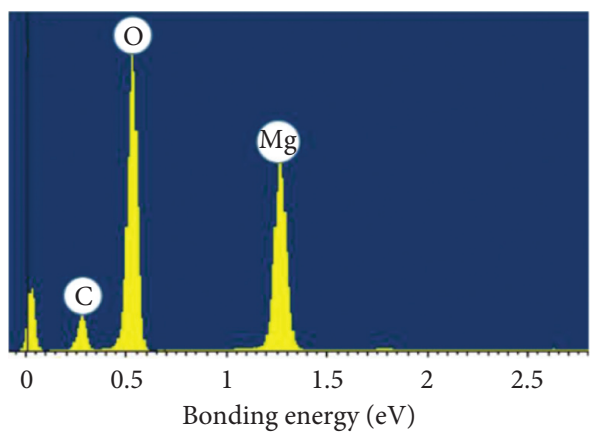

(d)

Figure 1: (a, b) Low- and high-magnification SEM images of the hollow MgO spheres; (c, d) XRD patterns and EDX spectrum of the hollow $\mathrm{MgO}$ spheres.

hexagonal structure $\mathrm{MgO}$ (JCPDS card no. 89-4248). Also, no peak for precursor hydromagnesium can be identified, indicating that the precursor is fully decomposed to $\mathrm{MgO}$. Figure 1(d) presents the representative EDS spectra of the $\mathrm{MgO}$ hollow spheres, and the molar ratio of $\mathrm{Mg}$ : $\mathrm{O}$ is $1: 1.13$, which is very close to the stoichiometry of $\mathrm{MgO}$. The structure of the $\mathrm{MgO}$ hollow spheres is further investigated by TEM and SAED. Figure 2(a) is the typical TEM image of the $\mathrm{MgO}$ sphere. The contrast of the deep outside and shallow inside definitely confirmed the hollow structure of the product. The thickness of the shell is about $30 \mathrm{~nm}$. Figure 2(b) is the high-magnification TEM image of the shell and reveals that the sphere is made up of huge number of nanoparticles. Moreover, there are many tiny mesopores on the shell, which is benefit to the adsorption performance of the product. From the HRTEM image presented in Figure 2(c), the fringe spacing of $0.24 \mathrm{~nm}$ can be ascribed to the (111) planes of the MgO. Figure 2(d) is the SAED pattern of the $\mathrm{MgO}$ spheres. A series of concentric rings with different radii can be seen, indicating the polycrystalline nature of the $\mathrm{MgO}$ hollow spheres.

3.2. Adsorption Properties. The fluoride adsorption performances of the $\mathrm{MgO}$ hollow spheres were systematically studied. Due to the hollow structure and porous surface, the as-prepared samples are expected with good adsorption properties. Figure 3(a) presents the fluoride adsorption kinetics of the $\mathrm{MgO}$ hollow spheres. It can be seen that the adsorption happens rapidly in the first $40 \mathrm{~min}$, where over
$83 \%$ of the fluoride ions can be adsorbed. Then, the adsorption capacity increases gradually until it reaches the equilibrium, where more than $95 \%$ of the fluoride ions can be removed by the $\mathrm{MgO}$ hollow spheres. To further quantify the changes of fluoride adsorption with time on the $\mathrm{MgO}$ hollow spheres, the Lagergren pseudo-first-order Model (1) [37] and Ho's pseudo-second-order Model (2) [38] were used to simulate the kinetics.

$$
\begin{gathered}
\ln q_{e}-q_{t}=\ln q_{e}-k_{1} t, \\
\frac{t}{q_{t}}=\frac{1}{k_{2} q_{e}^{2}}+\frac{t}{q_{e}},
\end{gathered}
$$

where $\mathrm{q}_{\mathrm{e}}$ and $q_{\mathrm{t}}$ are the amounts of adsorbed fluoride at equilibrium and at any time $t ; k_{1}$ and $k_{2}$ are the equilibrium rate constants for pseudo-first-order and pseudo-secondorder sorption.

The adsorption kinetic experimental data fitted into the pseudo-second-order model are presented in Figure 3(b). Also, Table 1 shows the summarized results fitted by the pseudo-first-order and pseudo-second-order models. The higher correlation coefficient value of the pseudo-secondorder model $\left(R^{2}=0.998\right)$ indicates that the fluoride adsorption kinetics of the $\mathrm{MgO}$ hollow spheres fit well with the pseudo-second-order kinetics model. When the initial fluoride concentration is $10 \mathrm{mg} / \mathrm{L}$, the equilibrium adsorption capacities (qe, cal) can be calculated as $9.54 \mathrm{mg} / \mathrm{g}$, which is in agreement with experimental equilibrium adsorption capacities. 


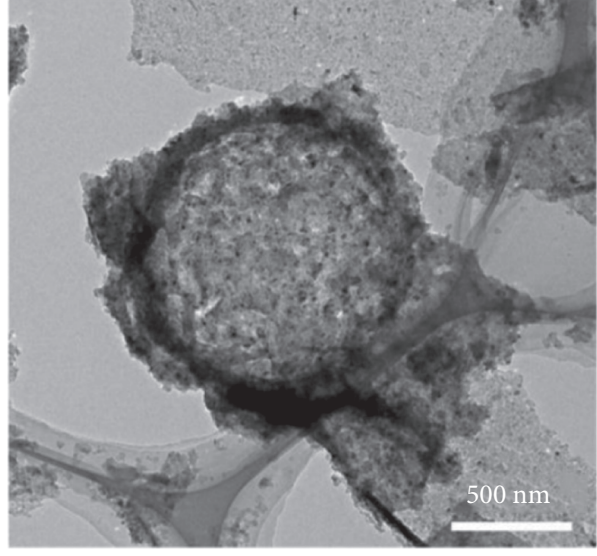

(a)

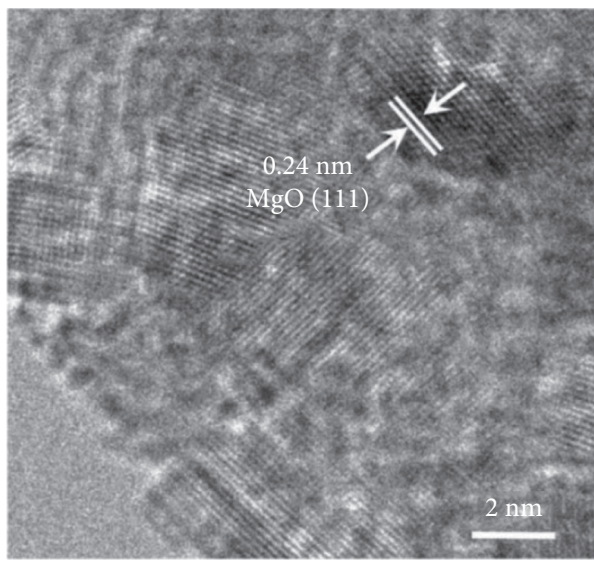

(c)

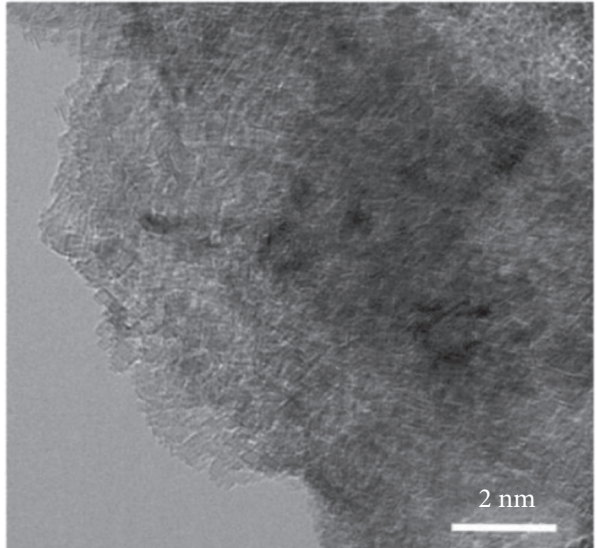

(b)

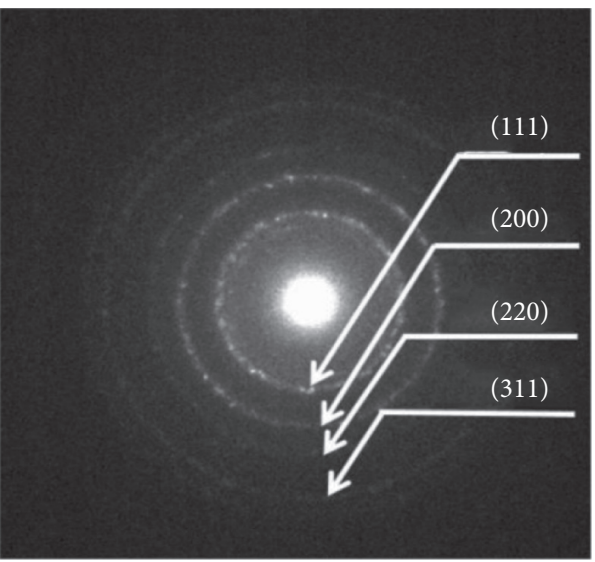

(d)

FIgURE 2: ( $\mathrm{a}, \mathrm{b})$ Different magnification TEM images of the hollow MgO sphere; $(\mathrm{c}, \mathrm{d})$ the corresponding HRTEM image and SAED pattern of the hollow $\mathrm{MgO}$ sphere.

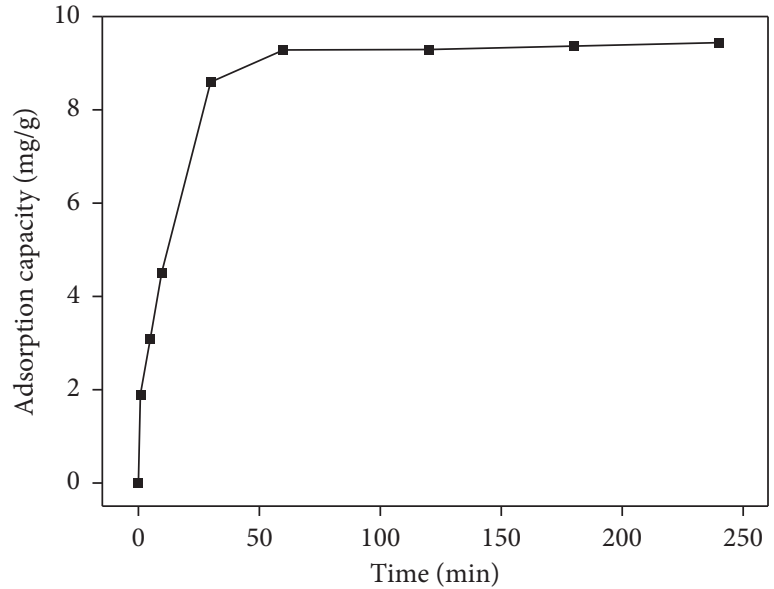

(a)

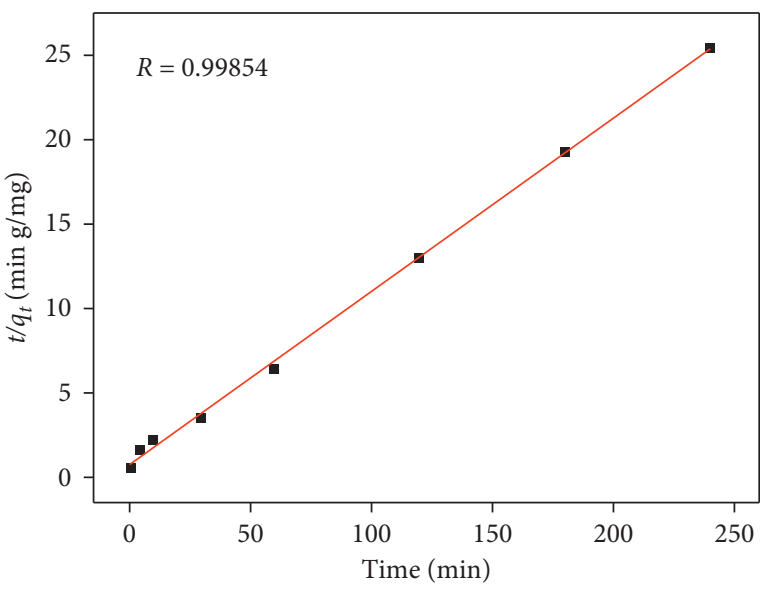

(b)

Figure 3: (a) Adsorption kinetics of fluoride removal by the hollow $\mathrm{MgO}$ spheres. (b) Pseudo-second-order fitting for fluoride removal by hollow MgO spheres $\left(\mathrm{pH}=7.0\right.$, dosage $\left.1 \mathrm{gL}^{-1}\right)$.

To further reveal the adsorption performance of the $\mathrm{MgO}$ hollow spheres, the fluoride adsorption isotherm is employed. The fluoride adsorption isotherm of the $\mathrm{MgO}$ hollow spheres is carried out at $\mathrm{pH}=7.0$, and the result is depicted in Figure 4(a). Obviously, when the concentration of the fluoride solution increases, the adsorption capacity of 
TABLE 1: Kinetic parameters for fluoride adsorption on the hollow MgO spheres.

\begin{tabular}{lcccccc}
\hline Equations & \multicolumn{3}{c}{$\begin{array}{c}\text { Pseudo-first-order kinetic model } \\
\ln \left(q_{e}-q_{t}\right)=\ln q_{e}-k_{1} t\end{array}$} & \multicolumn{3}{c}{$\begin{array}{c}\text { Pseudo-second-order kinetic model } \\
\left(t / q_{t}\right)=\left(1 / k_{2} q_{e}^{2}\right)+\left(t / q_{e}\right)\end{array}$} \\
$\begin{array}{lcccccc}\mathrm{C}_{0} \\
(\mathrm{mg} / \mathrm{L})\end{array}$ & $\begin{array}{c}k_{1} \\
(\mathrm{mg} / \mathrm{g})\end{array}$ & $(1 / \mathrm{min})$ & $\begin{array}{c}q_{e}, \mathrm{cal} \\
(\mathrm{mg} / \mathrm{g})\end{array}$ & $R^{2}$ & $\begin{array}{c}k_{2} \\
(\mathrm{~g} /(\mathrm{mg} \mathrm{min}))\end{array}$ & $\begin{array}{c}q_{e} \\
(\mathrm{mg} / \mathrm{g})\end{array}$ \\
\hline 10 & 9.43 & 0.028 & 4.65 & 0.775 & 0.015 & 9.54 \\
\hline
\end{tabular}

Note: $k_{1}$ is the adsorption rate constant for the pseudo-first-order reaction $(1 / \mathrm{min}) . k_{2}$ is the rate constant for the pseudo-second-order reaction $(\mathrm{g} /(\mathrm{mg} \mathrm{min})$ ). $q_{e}$ and $q_{t}$ are the amounts of solute sorbed at equilibrium and at any time $t(\mathrm{mg} / \mathrm{g})$, respectively. qe, exp is the adsorption capacity evaluated from batch experiment, while qe, cal is the adsorption capacity calculated on the basis of the pseudo-first-order and pseudo-second-order equations.

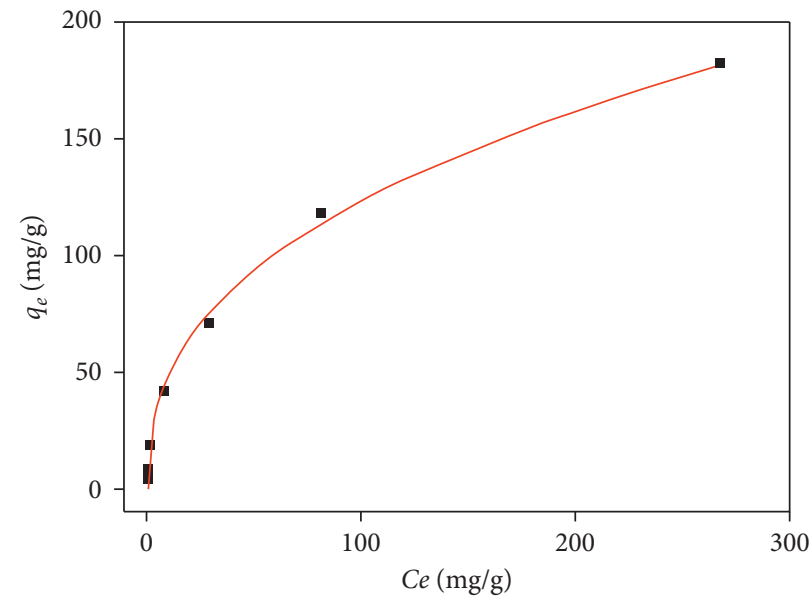

(a)

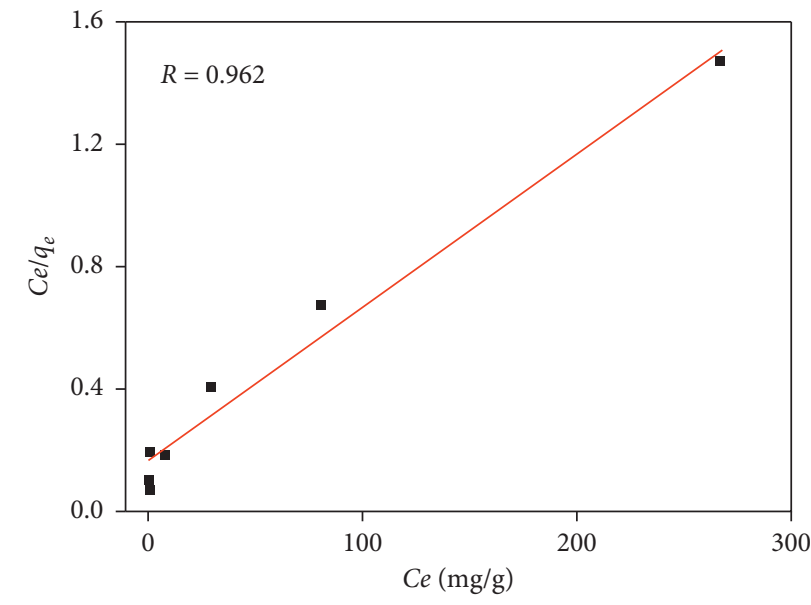

(b)

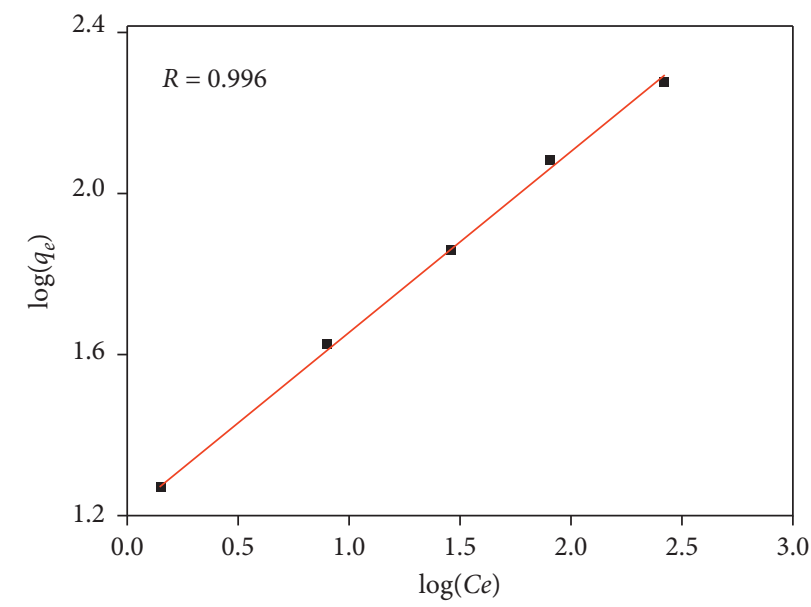

(c)

Figure 4: (a) Adsorption isotherm of fluoride on the hollow MgO spheres, (b, c) the corresponding Langmuir and Friedrish fitting (pH = 7.0 , dosage $\left.1 \mathrm{gL}^{-1}\right)$.

the $\mathrm{MgO}$ hollow spheres increases. The adsorption capacity of the spheres is $119.3 \mathrm{mg} / \mathrm{g}$ when the equilibrium concentration is $80.7 \mathrm{mg} / \mathrm{g}$. As the equilibrium concentration increases, the adsorption capacity of the $\mathrm{MgO}$ hollow spheres is larger than $182.4 \mathrm{mg} / \mathrm{g}$. Langmuir and Freundlich models are applied for data fitting, and the results are presented in Figures 4(b) and 4(c). Table 2 summarizes the isotherm parameters computed from the Langmuir and Freundlich models. The $R^{2}$ value of the Langmuir and Freundlich fitting model is 0.962 and 0.996 , respectively. The higher value of $R^{2}$ suggests that the fluoride adsorption isotherm of the $\mathrm{MgO}$ hollow spheres follows the Freundlich models. The results are similar with the previous reported $\mathrm{MgO}$ fluoride adsorbent [26]. A adsorption capacity comparison of different adsorbents is listed in Table 3. It can be seen that the $\mathrm{MgO}$ hollow spheres have a much higher adsorption capacity than other adsorbents. The excellent fluoride adsorption performance can be attributed to the hollow structure and porous surface. The hollow structure would bring relatively large surface area and more 


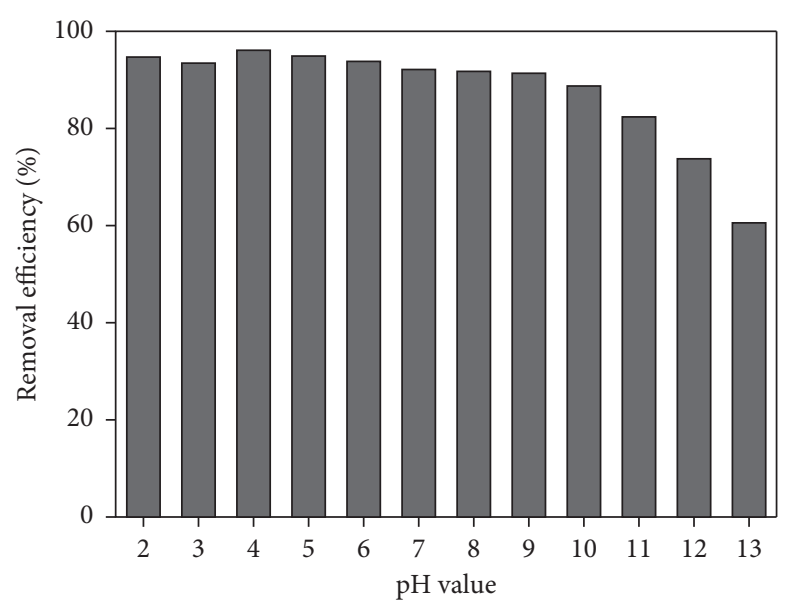

FIGURE 5: Effect of initial $\mathrm{pH}$ value on fluoride adsorption on the hollow $\mathrm{MgO}$ spheres (initial concentration of fluoride was $20 \mathrm{mgL}^{-1}$; the dosage of adsorbents was $\left.1 \mathrm{gL}^{-1}\right)$.

TABLE 2: Langmuir and Freundlich adsorption isotherm parameters for fluoride on the hollow MgO spheres.

\begin{tabular}{lccccc}
\hline Equations & \multicolumn{2}{c}{ Langmuir model } & \multicolumn{3}{c}{ Freundlich model } \\
Parameter & $q_{m}(\mathrm{mg} / \mathrm{g})$ & $q_{e}=q_{m} k_{L} C_{e} / 1+k_{L} C_{e}$ & & \multicolumn{2}{c}{$q_{e}=k_{F} C_{e}{ }^{1 / n_{F}}$} \\
$k_{L}(\mathrm{~L} / \mathrm{mg})$ & $R_{F}$ & $k_{F}(\mathrm{mg} / \mathrm{g})$ & $R^{2}$ \\
\hline Values & 200 & 0.030 & 0.962 & 162.9 & 2.73 \\
\hline
\end{tabular}

Note: $C_{e}$ is the equilibrium concentration of fluoride $(\mathrm{mg} / \mathrm{L}) ; q_{e}$ is the amount of fluoride adsorbed on per weight of adsorbent after equilibrium $(\mathrm{mg} / \mathrm{g}) ; q_{m}$ represents the maximum adsorption capacity of fluoride on per weight of adsorbent $(\mathrm{mg} / \mathrm{g}) ; k_{L}$ is the Langmuir constant related to the energy of adsorption $(\mathrm{L} / \mathrm{mg}) ; q_{m}$ and $k_{L}$ were calculated from the slope and intercept of the linear plots of $C_{e} / q_{e}$ vs $C_{e}$. The Freundlich constant $k$ is correlated to the relative adsorption capacity of the adsorbent $(\mathrm{mg} / \mathrm{g})$, and $1 / n$ is the adsorption intensity.

TABle 3: Comparison of the fluoride adsorption properties of various adsorbents.

\begin{tabular}{|c|c|c|c|c|}
\hline Adsorbents & Adsorption capacity (mg/g) & Dose $(\mathrm{g} / \mathrm{L})$ & $\mathrm{pH}$ & Ref. \\
\hline Alumina & 83.3 & 1 & 6 & [17] \\
\hline Mg-Al bimetallic oxides & 89.3 & 1 & 6 & [39] \\
\hline Zirconium oxide & 19 & 20 & 4.75 & {$[40]$} \\
\hline Fe-Zr hybrid oxide & 7.5 & 1 & 6 & {$[41]$} \\
\hline $\mathrm{CeO}_{2}-\mathrm{ZrO}_{2}$ nanocages & 175 & 0.2 & 4 & {$[42]$} \\
\hline Al-Ce hybrid & 27.7 & 0.1 & 6 & {$[43]$} \\
\hline $\mathrm{Fe}_{2} \mathrm{O}_{3} \cdot \mathrm{Al}_{2} \mathrm{O}_{3} \cdot \mathrm{xH}_{2} \mathrm{O}$ & 30 & 2 & 4 & {$[44]$} \\
\hline Aluminum-modified hydroxyapatite & 32.57 & 5 & 7 & {$[15]$} \\
\hline $\mathrm{MgO} /$ chitosan & $>4.44$ & 2 & 7 & {$[45]$} \\
\hline Commercial MgO powder & $>45.2$ & 1 & 7 & Present work \\
\hline Hierarchical MgO microspheres & $>182.4$ & 1 & 7 & Present work \\
\hline
\end{tabular}

active sites for fluoride adsorption. Commonly, the adsorbents work when its surfaces contact with the fluoride solution, indicating that only the outer surface of normal sphere works during the adsorption process. However, the $\mathrm{MgO}$ hollow spheres have two surfaces, an inner and outer surface. They both can work during the fluoride adsorption process, which largely improve the utilization of the adsorbents. Furthermore, the porous structure can provide abundant channels for fluoride ion diffusion, which would efficiently improve the adsorption performance of the absorbent.

It is well accepted that the $\mathrm{pH}$ value of the fluoride solution can largely affect the performance of the adsorbents. Thus, the fluoride adsorption property of the
$\mathrm{MgO}$ hollow spheres were studied under different $\mathrm{pH}$ values. It can be seen from Figure 4 that, within $2-10$, the $\mathrm{pH}$ value has little influence on the fluoride removal efficiency of the $\mathrm{MgO}$ hollow spheres. However, when the $\mathrm{pH}$ value is beyond 11, the fluoride removal efficiency of the absorbent dramatically decreases. The quick reduction of fluoride removal efficiency of the MgO hollow spheres in the alkaline condition could be attributed to competition of hydroxyl ions with fluoride for adsorption sites [46].

In practical application, various anions exist in the actual groundwater; thus, it is useful to investigate the interference of coexisting ions on the fluoride adsorption of $\mathrm{MgO}$ hollow spheres. As presented in Figure 6, these anions at different 


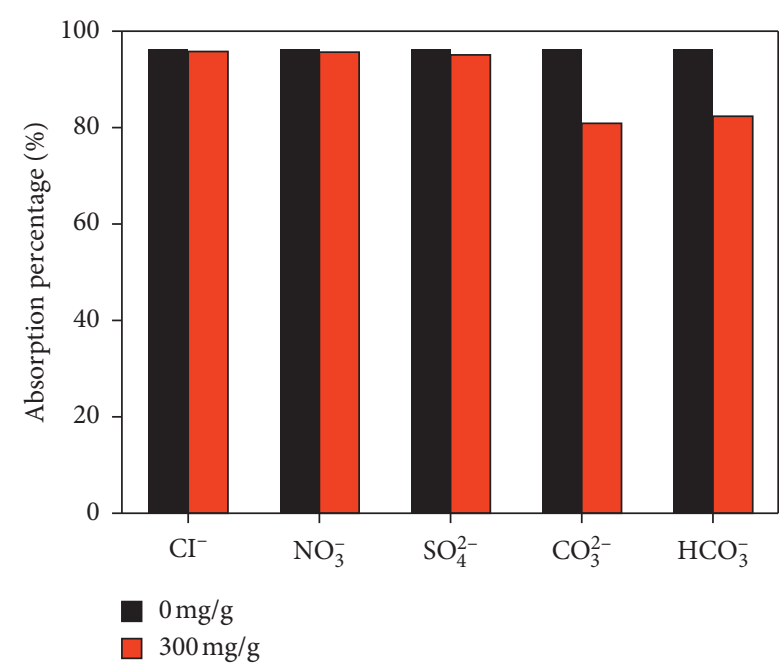

Figure 6: Effect of the competing anions on the hollow $\mathrm{MgO}$ spheres (initial concentration of fluoride was $20 \mathrm{mgL}^{-1}$; the dosage of adsorbents was $1 \mathrm{gL}^{-1}$ ).

concentrations have different effects on the fluoride adsorption. $\mathrm{Cl}^{-}, \mathrm{SO}_{4}{ }^{2-}$, and $\mathrm{NO}_{3}{ }^{-}$have shown a negligible effect on fluoride adsorption. However, the $\mathrm{CO}_{3}{ }^{2-}$ and $\mathrm{HCO}_{3}{ }^{-}$ions can largely effect the adsorption performance of the $\mathrm{MgO}$ hollow spheres.

3.3. Adsorption Mechanism. To reveal the adsorption mechanism, zeta potential analysis was firstly employed. Figure 7 presents the zeta potential of the MgO hollow spheres at different $\mathrm{pH}$ values. When the $\mathrm{pH}=2$, the zeta potential of the sample is $13.8 \mathrm{eV}$. Under acidic conditions, as the $\mathrm{pH}$ value increases, the zeta potential of the $\mathrm{MgO}$ hollow spheres slightly decreases. However, when the $\mathrm{pH}$ value continuously increases to alkaline, the zeta potential of the $\mathrm{MgO}$ hollow spheres drops sharply. It can be seen that the zero point of potential of the $\mathrm{MgO}$ hollow spheres is close to $\mathrm{pH} 10$. The higher zero point of the $\mathrm{MgO}$ hollow spheres is benefit to the fluoride adsorption via electrostatic attraction, subsequently resulting in the good fluoride adsorption performance in neutral and even weak alkaline conditions.

Obviously, only zeta potential is inadequate to illustrate the adsorption mechanism of the MgO hollow spheres; thus, the FTIR analysis was also employed. Figure 8 indicates the FTIR spectra of the $\mathrm{MgO}$ hollow spheres before and after fluoride adsorption. There are a broad-band peak located at $3466 \mathrm{~cm}^{-1}$ and a relatively small peak located at $1641 \mathrm{~cm}^{-1}$ existing in both the samples, which correspond to the stretching vibration modes of $\mathrm{OH}$ bands and the bending vibration of the $\mathrm{H}-\mathrm{O}-\mathrm{H}$ band of the adsorbed water, respectively [43]. After fluoride adsorption, the FTIR peak at $3695 \mathrm{~cm}^{-1}$ become strong, suggesting the formation of $\mathrm{Mg}(\mathrm{OH})_{2}$ on the surface of $\mathrm{MgO}$ hollow spheres during the adsorption process [47]. Furthermore, before fluoride adsorption, the peak at $429.7 \mathrm{~cm}^{-1}$ can be obviously observed, which corresponds to the $\mathrm{Mg}-\mathrm{O}$ stretching vibration.

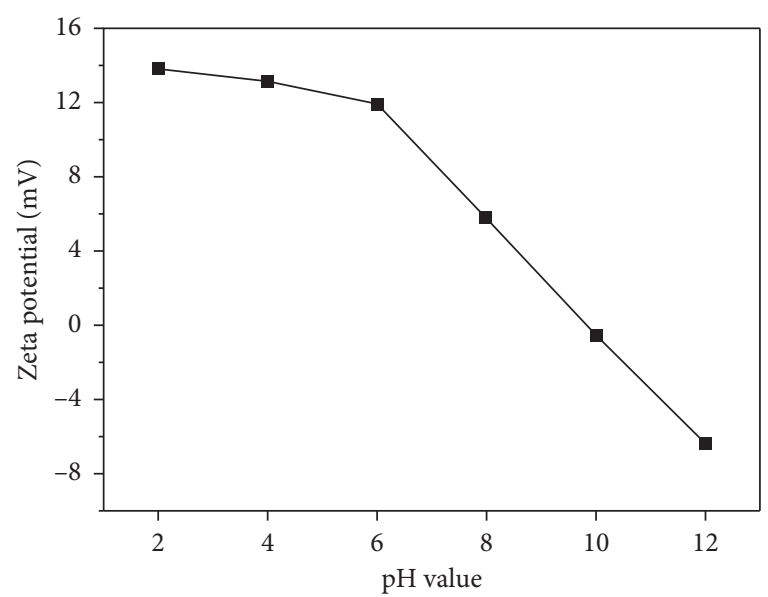

FIgURE 7: The zeta potential of the hollow $\mathrm{MgO}$ spheres at different $\mathrm{pH}$ values.

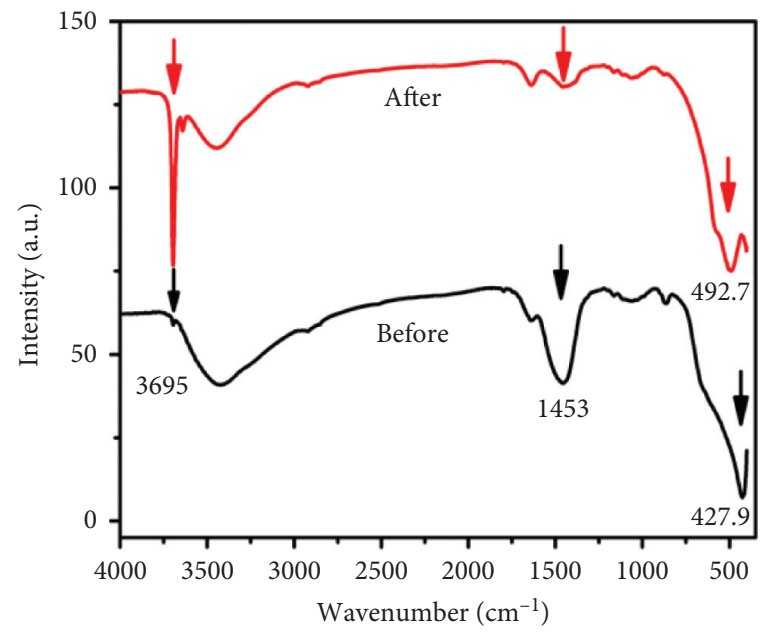

FIgURE 8: The FTIR spectra of the hollow MgO spheres after treated in aqueous and fluoride-contained solutions for $12 \mathrm{~h}$.

However, after adsorption, the peak at $429.7 \mathrm{~cm}^{-1}$ vanishes, and a new peak at $492.7 \mathrm{~cm}^{-1}$ appears. The new peak can be assigned to the Mg-F stretching vibration, indicating that $\mathrm{MgF}$ forms during the adsorption process. For the $\mathrm{MgO}$ hollow spheres, the peak at $1453 \mathrm{~cm}^{-1}$ can be clearly observed, which corresponds to the asymmetric stretching vibration of carbonates [48]. $\mathrm{MgO}$, as basic oxide, easily reacts with the $\mathrm{CO}_{2}$ molecule in the air, forming a magnesium carbonate species on its surface [26]. It is noteworthy that, after adsorption, the intensity of the peak at $1453 \mathrm{~cm}^{-1}$ largely decreases, indicating the great reduction of the surface carbonates during the fluoride adsorption process. The hydroxyl exchange adsorption mechanism is well accepted in fluoride adsorption. In our case, we also found that the surface carbonates also can be exchanged with $\mathrm{F}^{-}$during the adsorption process.

As presented in Figure 9, the schematic fluoride adsorption mechanism is proposed on the $\mathrm{MgO}$ hollow spheres. It is well accepted that the $\mathrm{MgO}$ can react with 


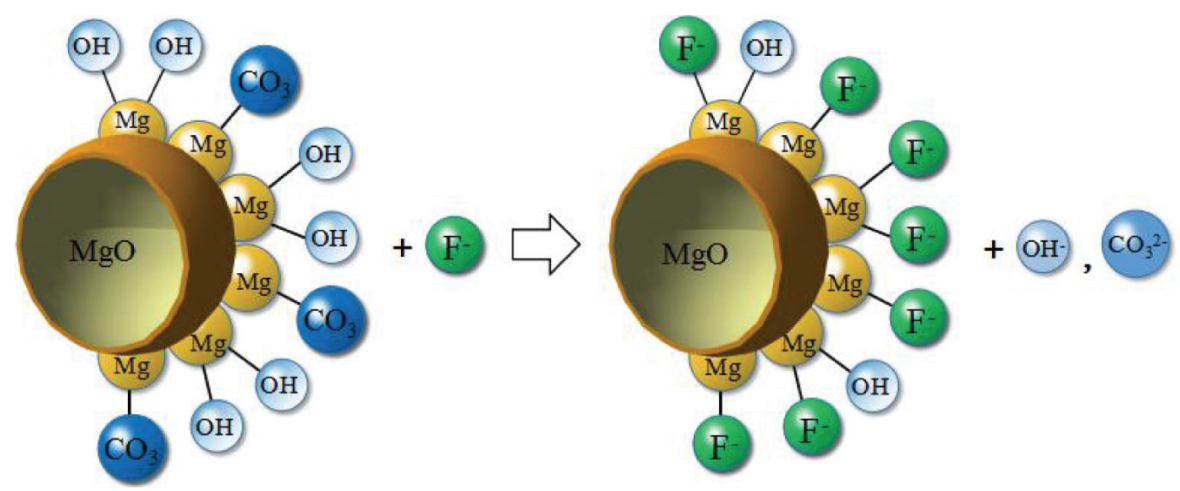

Figure 9: The fluoride removal mechanism of the hollow MgO spheres.

$\mathrm{H}_{2} \mathrm{O}$, forming $\mathrm{MgOH}$ on the surface. By exchanging with the surface hydroxyls, fluoride ions can be adsorbed on the surface. In acidic condition, the large amount of $\mathrm{H}^{+}$ ions are conducive to the adsorption equilibrium; thus, the $\mathrm{MgO}$ hollow spheres exhibit higher adsorption property in acidic condition. When the $\mathrm{pH}$ value increase, the redundant hydroxyl ions are not in favor for the fluoride removal, which will result in the decrease of the removal capacity. Furthermore, due to the preparation environment, there is a considerable quantity of carbonates adsorbed on the surface of $\mathrm{MgO}$ hollow spheres. During the adsorption process, those surface carbonates also can exchange with the fluoride ions in the water, which is benefit to the adsorption property of the absorbents. The coexchange of the hydroxyls and surface carbonates would largely increase the adsorption performance of the $\mathrm{MgO}$ hollow spheres in neutral and alkaline conditions. In this way, the $\mathrm{MgO}$ hollow spheres the exhibit superior performance in fluoride adsorption over a wide $\mathrm{pH}$ range.

\section{Conclusions}

In conclusion, the $\mathrm{MgO}$ hollow spheres have been synthesized via a facile wet-chemistry method. The hollow and porous structure endorses the $\mathrm{MgO}$ hollow spheres the good fluoride adsorption property. The removal efficiency of the $\mathrm{MgO}$ hollow spheres to fluoride is very fast, and the result can be well fitted into the pseudo-secondorder rate kinetic model. The adsorption capacity of the $\mathrm{MgO}$ hollow spheres is larger than $182.4 \mathrm{mg} / \mathrm{g}$ at $\mathrm{pH} 7.0$. The $\mathrm{MgO}$ hollow spheres maintain excellent fluoride adsorption performance over a wide $\mathrm{pH}$ range. From the FTIR results, a hydroxyl and carbonate coexchange mechanism is proposed. It is believed that the as-prepared $\mathrm{MgO}$ hollow spheres can be a potential candidate for fluoride removal.

\section{Data Availability}

The raw data required to reproduce these findings cannot be shared at this time as the data also form part of an ongoing study.

\section{Conflicts of Interest}

The authors declare that they have no conflicts of interest.

\section{Acknowledgments}

The authors gratefully acknowledge the financial support provided by the National Key Research and Development Program (No. 2019YFC0408504), Natural Science Foundation of Anhui Province (No. 2008085MB44), Natural Science Research Project of Anhui Educational Committee (Nos. KJ2019A0772 and KJ2018ZD048), Initial Scientific Research Fund of Anhui Jianzhu University (No. 2017QD14), and Science and Technology Service Network Initiative of the Chinese Academy of Sciences (No. KFJ-STSQYZD-173).

\section{References}

[1] J. Jankausk, "Effects of fluoride on kidney review," Fluoride, vol. 7, no. 2, pp. 93-105, 1974, in English.

[2] X. L. Zhao, "Removal of fluoride from aqueous media by $\mathrm{Fe}_{3} \mathrm{O}_{4} @ \mathrm{AlOH}_{3}$ magnetic nanoparticles, in English," Journal of Hazardous Materials, vol. 173, no. 1-3, pp. 102-109, 2010.

[3] K. Hu and J. M. Dickson, "Nanofiltration membrane performance on fluoride removal from water, in English," Journal of Membrane Science, vol. 279, no. 1-2, pp. 529-538, 2006.

[4] WHO, Guidelines for drinking-water quality: incorporating first addendum, WHO, Geneva, Switzerland, 2006.

[5] Z. JinT. Jia et al., "Efficient removal of fluoride by hierarchical MgO microspheres: performance and mechanism study," Applied Surface Science, vol. 357, pp. 1080-1088, 2015.

[6] B. D. Turner, P. Binning, and S. L. S. Stipp, "Fluoride removal by calcite: evidence for fluorite precipitation and surface adsorption," Environmental Science \& Technology, vol. 39, no. 24, pp. 9561-9568, 2005.

[7] B. Pan, J. Xu, B. Wu, Z. Li, and X. Liu, "Enhanced removal of fluoride by polystyrene anion exchanger supported hydrous zirconium oxide nanoparticles," Environmental Science \& Technology, vol. 47, no. 16, pp. 9347-9354, 2013.

[8] C. S. Sundaram and S. Meenakshi, "Fluoride sorption using organic-inorganic hybrid type ion exchangers, in English," Journal of Colloid and Interface Science, vol. 333, no. 1, pp. 58-62, 2009. 
[9] W. F. Ma, W. J. Liu, and G. W. Chen, "Factors influencing the removal of fluoride from groundwater by nanofiltration," in Proceedings of the 2009 3rd International Conference on Bioinformatics and Biomedical Engineering, vol. 1-11, pp. 5771-5775, Beijing, China, June 2009.

[10] L. A. Richards, M. Vuachère, and A. I. Schäfer, "Impact of pH on the removal of fluoride, nitrate and boron by nanofiltration/reverse osmosis," Desalination, vol. 261, no. 3, pp. 331-337, 2010.

[11] I. Bejaoui, A. Mnif, and B. Hamrouni, "Performance of reverse osmosis and nanofiltration in the removal of fluoride from model water and metal packaging industrial effluent," Separation Science and Technology, vol. 49, no. 8, pp. 1135-1145, 2014.

[12] L. J. Banasiak and A. I. Schafer, "Removal of boron, fluoride and nitrate by electrodialysis in the presence of organic matter, in English," Journal of Membrane Science, vol. 334, no. 1-2, pp. 101-109, 2009.

[13] M. Arda, E. Orhan, O. Arar, M. Yuksel, and N. Kabay, "Removal of fluoride from geothermal water by electrodialysis ED," Separation Science and Technology, vol. 44, no. 4, pp. 841-853, 2009.

[14] L. Chen, B.-Y. He, S. He, T.-J. Wang, C.-L. Su, and Y. Jin, "Fe-Ti oxide nano-adsorbent synthesized by co-precipitation for fluoride removal from drinking water and its adsorption mechanism," Powder Technology, vol. 227, pp. 3-8, 2012.

[15] Y. Nie, C. Hu, and C. Kong, "Enhanced fluoride adsorption using Al III modified calcium hydroxyapatite," Journal of Hazardous Materials, vol. 233-234, pp. 194-199, 2012.

[16] S. Mandal and S. Mayadevi, "Cellulose supported layered double hydroxides for the adsorption of fluoride from aqueous solution," Chemosphere, vol. 72, no. 6, pp. 995-998, 2008.

[17] W.-X. Gong, J.-H. Qu, R.-P. Liu, and H.-C. Lan, "Adsorption of fluoride onto different types of aluminas," Chemical Engineering Journal, vol. 190, pp. 126-133, 2012.

[18] S. Ghorai and K. K. Pant, "Investigations on the column performance of fluoride adsorption by activated alumina in a fixed-bed, in English," Chemical Engineering Journal, vol. 98, no. 1-2, pp. 165-173, 2004.

[19] D. Zhang, H. Luo, L. Zheng et al., "Utilization of waste phosphogypsum to prepare hydroxyapatite nanoparticles and its application towards removal of fluoride from aqueous solution," Journal of Hazardous Materials, vol. 241-242, pp. 418-426, 2012.

[20] M. G. Sujana and S. Anand, "Fluoride removal studies from contaminated ground water by using bauxite," Desalination, vol. 267, no. 2-3, pp. 222-227, 2011.

[21] S. Meenakshi, C. S. Sundaram, and R. Sukumar, "Enhanced fluoride sorption by mechanochemically activated kaolinites, in English," Journal of Hazardous Materials, vol. 153, no. 1-2, pp. 164-172, 2008.

[22] A. Bhatnagar, E. Kumar, and M. Sillanpää, "Fluoride removal from water by adsorption-A review," Chemical Engineering Journal, vol. 171, no. 3, pp. 811-840, 2011.

[23] Y. Ku and H. M. Chiou, "The adsorption of fluoride ion from aqueous solution by activated alumina," Water Air and Soil Pollution, vol. 133, no. 1-4, pp. 349-360, 2002.

[24] Y. H. Li et al., "Adsorption of fluoride from water by amorphous alumina supported on carbon nanotubes, in English," Chemical Physics Letters, vol. 350, no. 5-6, pp. 412-416, 2001.

[25] J. Wang, W. Xu, L. Chen et al., "Excellent fluoride removal performance by $\mathrm{CeO} 2-\mathrm{ZrO} 2$ nanocages in water environment," Chemical Engineering Journal, vol. 231, pp. 198-205, 2013.

[26] K. Sasaki, N. Fukumoto, S. Moriyama, Q. Yu, and T. Hirajima, "Chemical regeneration of magnesium oxide used as a sorbent for fluoride," Separation and Purification Technology, vol. 98, pp. 24-30, 2012.

[27] Z. Jin, Y. Jia, K.-S. Zhang et al., "Effective removal of fluoride by porous $\mathrm{MgO}$ nanoplates and its adsorption mechanism," Journal of Alloys and Compounds, vol. 675, pp. 292-300, 2016.

[28] J. Kang, B. Li, J. Song et al., "Defluoridation of water using calcined magnesia/pullulan composite," Chemical Engineering Journal, vol. 166, no. 2, pp. 765-771, 2011.

[29] S. M. Maliyekkal, S. Shukla, L. Philip, and I. M. Nambi, "Enhanced fluoride removal from drinking water by magnesia-amended activated alumina granules, in English," Chemical Engineering Journal, vol. 140, no. 1-3, pp. 183-192, 2008.

[30] K. Zhang, S. Wu, X. Wang et al., "Wide $\mathrm{pH}$ range for fluoride removal from water by $\mathrm{MHS}-\mathrm{MgO} / \mathrm{MgCO}_{3}$ adsorbent: kinetic, thermodynamic and mechanism studies," Journal of Colloid and Interface Science, vol. 446, pp. 194-202, 2015.

[31] S. Lan, L. Liu, R. Li, Z. Leng, and S. Gan, "Hierarchical hollow structure $\mathrm{ZnO}$ : synthesis, characterization, and highly efficient adsorption/photocatalysis toward Congo red," Industrial \& Engineering Chemistry Research, vol. 53, no. 8, pp. 3131-3139, 2014.

[32] M. Huang, R. Zhang, Z. Yang et al., "Synthesis of $\mathrm{Co}_{3} \mathrm{~S}_{4}-\mathrm{SnO}_{2} /$ polyvinylpyrrolidone-cellulose heterojunction as highly performance catalyst for photocatalytic and antimicrobial properties under ultra-violet irradiation," International Journal of Biological Macromolecules, vol. 162, pp. 220-228, 2020.

[33] Y. F. Yang, M. A. Ashraf, A. Fakhri, V. K. Gupta, and D. Q. Zhang, "Facile synthesis of gold-silver/copper sulfide nanoparticles for the selective/sensitive detection of chromium, photochemical and bactericidal application," Spectrochimica Acta Part A-Molecular and Biomolecular Spectroscopy, vol. 249, Article ID 119324, 2021.

[34] S. Lan, N. Guo, L. Liu, X. Wu, L. Li, and S. Gan, "Facile preparation of hierarchical hollow structure gamma alumina and a study of its adsorption capacity," Applied Surface Science, vol. 283, pp. 1032-1040, 2013.

[35] M. Kuang, Y. Shang, G. Yang, B. Liu, and B. Yang, "Facile synthesis of hollow mesoporous $\mathrm{MgO}$ spheres via spraydrying with improved adsorption capacity for PbII and CdII," Environmental Science and Pollution Research, vol. 26, no. 18, pp. 18825-18833, 2019.

[36] S. Yang, P. Huang, L. Peng et al., "Hierarchical flowerlike magnesium oxide hollow spheres with extremely high surface area for adsorption and catalysis," Journal of Materials Chemistry A, vol. 4, no. 2, pp. 400-406, 2016.

[37] S. Lagergren, "About the theory of so-called adsorption of soluble substances, K," Svenska VetenskapsakadHandl, vol. 24, pp. 1-39, 1898.

[38] Y.-S. Ho, "Second-order kinetic model for the sorption of cadmium onto tree fern: a comparison of linear and nonlinear methods," Water Research, vol. 40, no. 1, pp. 119-125, 2006.

[39] S. Moriyama, K. Sasaki, and T. Hirajima, "Effect of calcination temperature on $\mathrm{Mg}$ - $\mathrm{Al}$ bimetallic oxides as sorbents for the removal of $\mathrm{F}-$ in aqueous solutions," Chemosphere, vol. 95, pp. 597-603, 2014.

[40] J. A. Blackwell and P. W. Carr, "Study of the fluoride adsorption characteristics of porous microparticulate zirconium 
oxide," Journal of Chromatography A, vol. 549, no. 1-2, pp. 43-57, 1991.

[41] K. Biswas, D. Bandhoyapadhyay, and U. C. Ghosh, "Adsorption kinetics of fluoride on ironIII-zirconiumIV hybrid oxide," Adsorption, vol. 13, no. 1, pp. 83-94, 2007.

[42] X. Wu, Y. Zhang, X. Dou, and M. Yang, "Fluoride removal performance of a novel Fe-Al-Ce trimetal oxide adsorbent," Chemosphere, vol. 69, no. 11, pp. 1758-1764, 2007.

[43] H. Liu, S. B. Deng, Z. J. Li, G. Yu, and J. Huang, "Preparation of Al-Ce hybrid adsorbent and its application for defluoridation of drinking water," Journal of Hazardous Materials, vol. 179, no. 1-3, pp. 424-430, 2010.

[44] N. I. Chubar, V. F. Samanidou, V. S. Kouts et al., "Adsorption of fluoride, chloride, bromide, and bromate ions on a novel ion exchanger," Journal of Colloid and Interface Science, vol. 291, no. 1, pp. 67-74, 2005.

[45] C. S. Sundaram, N. Viswanathan, and S. Meenakshi, "Defluoridation of water using magnesia/chitosan composite, in English," Journal of Hazardous Materials, vol. 163, no. 2-3, pp. 618-624, 2009.

[46] D. Dayananda, V. R. Sarva, S. V. Prasad, J. Arunachalam, P. Parameswaran, and N. N. Ghosh, "Synthesis of $\mathrm{MgO}$ nanoparticle loaded mesoporous $\mathrm{Al}_{2} \mathrm{O}_{3}$ and its defluoridation study," Applied Surface Science, vol. 329, pp. 1-10, 2015.

[47] H. Niu, Q. Yang, K. Tang, and Y. Xie, "Large-scale synthesis of single-crystalline $\mathrm{MgO}$ with bone-like nanostructures," Journal of Nanoparticle Research, vol. 8, no. 6, pp. 881-888, 2006.

[48] R. Xu and H. C. Zeng, "Dimensional control of cobalt-hydroxidecarbonate nanorods and their thermal conversion to one-dimensional arrays of $\mathrm{Co}_{3} \mathrm{O}_{4}$ Nanoparticles," The Journal of Physical Chemistry B, vol. 107, no. 46, pp. 12643-12649, 2003. 